\title{
A Cross-sectional Survey of Patients with Suspected Diabetic Peripheral Neuropathic Pain in Japan
}

\author{
Hideyuki Sasaki ${ }^{1}$, Hiroshi Takatsuna ${ }^{2}$, Teruyoshi Inoue ${ }^{2}$, Daiju Matsui ${ }^{2}$, Hiroshi Sakoda ${ }^{2}$, \\ Mizuka Yokoyama ${ }^{2}$, Kazuhito Shiosakai ${ }^{3}$, Haruhiko Seki ${ }^{4}$, \\ Yoshiyuki Uetake $^{4}$ and Kaoru Okuizumi ${ }^{2}$
}

\begin{abstract}
:
Objective The burden of diabetic peripheral neuropathic pain (DPNP) is poorly understood. The present study reported on the current status of DPNP in Japan, to improve our understanding of this condition among healthcare providers and inform future clinical research on its prevalence, diagnosis, and management.

Methods A cross-sectional, observational study (UMIN000037023) was conducted via a web-based survey. The primary endpoints were the frequency of patients with bilateral foot symptoms, consulting a doctor, understanding DPNP, and reporting problems in daily life, as well as the treatment awareness of patients.

Patients Adults $\geq 20$ years old who were registered in the Rakuten Insight Disease Panel and receiving antidiabetic therapy in Japan were included.

Results Bilateral foot pain symptoms were reported by 1,768/7,754 (22.8\%) respondents, most commonly intense numbness (13.0\%). Of those with symptoms, 55.3\% consulted a doctor; the most common reason for not seeking consultation was feeling that symptoms were insufficiently severe to bother their doctor $(89.4 \%)$. Nearly $60 \%$ reported understanding the causes of their symptoms, with diabetes-associated neurologic deficits (58.8\%) most commonly identified. About one-quarter reported daily life problems, including an inability to walk for long periods $(58.3 \%)$ and feeling anxious (58.1\%). Treatment awareness was reported by $18.2 \%$; oral medications were commonly recognized $(64.6 \%)$.

Conclusion In Japan, $22.8 \%$ of patients with diabetes have bilateral foot pain symptoms; some experience problems in their daily life without understanding the causes of their symptoms. This supports the importance of actions to increase awareness and minimize DPNP-associated impairment of daily life in patients with diabetes.
\end{abstract}

Key words: cross-sectional study, diabetic peripheral neuropathic pain, web survey, Japan

(Intern Med 60: 357-365, 2021)

(DOI: 10.2169/internalmedicine.5512-20)

\section{Introduction}

Diabetic peripheral neuropathy (DPN) is a common complication of diabetes mellitus (1), with an estimated prevalence in patients with diabetes mellitus of $28 \%$ in the US $(2,3)$, between $6 \%$ and $34 \%$ in Europe (4), and between $28 \%$ and $37 \%$ in Japan (5-7). Diabetic peripheral neuro- pathic pain (DPNP), one of the symptoms of DPN, is associated with numbness, pain, and abnormal sensation often occurring below the knees of both legs (8). DPNP is also associated with sleep impairment, depression, and anxiety and has a detrimental effect on patients' quality of life (QOL) (9-11).

Despite its high prevalence and detrimental effect on patients' QOL, DPNP is thought to be both underdiagnosed

${ }^{1}$ Division of Diabetes and Metabolism, Satellite Clinic for Integrative and Anti-Aging Medicine, Wakayama Medical University, Japan, ${ }^{2}$ Medical Affairs Division, Daiichi Sankyo Co., Ltd., Japan, ${ }^{3}$ Digital Transformation Management Division, Daiichi Sankyo Co., Ltd., Japan and ${ }^{4}$ INTAGE Healthcare Inc., Japan

Received: June 3, 2020; Accepted: July 21, 2020; Advance Publication by J-STAGE: September 12, 2020

Correspondence to Dr. Kaoru Okuizumi, okuizumi.kaoru.tr@daiichisankyo.co.jp 
and undertreated in clinical settings (12). The 2016 Diabetes Care Guidelines from the Japan Diabetes Society (JDS) (13) recommend simple diagnostic examinations, such as Achilles tendon reflex and vibration sensation tests, for the determination of DPN. However, studies indicate that implementation rates of diagnostic tests are low $(14,15)$. As a result, many doctors may be unaware that their patients have DPN (16), and the majority of patients have not historically received drug therapy for their pain symptoms (15).

Recently, several analgesics have become available for the treatment of neuropathic pain, including calcium channel alpha-2-delta $\left(\alpha_{2} \delta\right)$ ligands and serotonin-norepinephrine reuptake inhibitors (SNRIs) $(13,16-18)$, and their use is gradually increasing. These treatments are now recommended as first-line therapies for patients with symptoms $(17,19-26)$.

Unfortunately, few reports have evaluated the prevalence of DPNP and its impact on the QOL, including in Japan. In addition, since the advent of the new therapeutics, no largescale study has been conducted, and available data are over a decade old $(14,27)$. A number of internet-based surveys have attempted to characterize the burden of diabetes and DPNP among various diabetic patient populations (27-31). Web-based surveys, while carrying some inherent limitations, enable access to relatively rapid, easy-to-collect, easyto-analyze, large-scale data that can provide a broad and valuable overview. Published surveys have assessed the prevalence of suspected DPNP, types of pain and drugs used, and diagnosis status. Importantly, some surveys have described a widespread lack of understanding among patients that neuropathic pain is a potential consequence of untreated diabetes $(28,29)$. However, some important data are lacking among these survey publications, including detailed evaluations on the degree of patient understanding, degree of pain intensity, reasons for not receiving a doctor's diagnosis, or the effects of DPNP on QOL. Therefore, thoroughly investigating and clarifying such issues in patients with suspected DPNP is critical for improving our awareness of the impact of DPNP and the importance of treatment.

This observational study used a web-based questionnaire to directly survey patients from Japan with suspected DPNP regarding their experiences. The purpose was to provide a contemporary analysis of the current status of DPNP in Japan, including in clinical practice. The ultimate goals of this study were to contribute to an improved understanding of DPNP among healthcare providers and to collect information to serve as the basis for clinical research on the diagnosis and treatment of patients with DPNP.

\section{Materials and Methods}

\section{Study design and patients}

This was a cross-sectional, observational, web-based questionnaire study to investigate the current status of suspected DPNP in Japan. Patients $\geq 20$ years old who were registered in the Rakuten Insight Disease Panel (with type 1 diabetes, type 2 diabetes, or other types of diabetes) and who were receiving oral or injectable anti-diabetic drugs were included (32). Enrolled patients self-reported a diagnosis of diabetes, and confirmation of diagnosis was not required; however, prescription of anti-diabetic therapy as an inclusion criterion implied a definitive diagnosis of diabetes by a medical professional. To minimize the possibility of artificial responses and to obtain highly reliable survey results, patients were excluded if they were involved in market research or advertising/marketing, were members of the news media, were healthcare providers, or were employees of pharmaceutical companies.

\section{Outcomes}

The primary endpoints were the number and percentage of patients (i) with bilateral foot symptoms, (ii) who consulted a doctor, (iii) who understood the disease (DPNP), (iv) who reported problems in their daily life, and (v) who were aware of treatment [with (i) provided as five levels of pain on a pain severity scale and (ii) to (iv) as yes or no answers]. The secondary endpoints were the reasons and detailed information regarding why yes or no was answered for each primary endpoint (i.e. reasons for not consulting a doctor and understanding of DPNP, and detailed content regarding problems in their daily life and awareness of treatment).

Patient and disease baseline characteristics were collected, including sex, age, region of residence, type of diabetes, history of diabetes, most recent hemoglobin A1c (HbA1c) value, smoking and drinking frequency, healthcare consultation (status, department, type of medical institution), and history of symptoms in both feet. Questions from A to Q5_1 were answered by all patients using the neuropathic pain screening questionnaire developed in Japan (33). For Q5_1, pain in the legs (below the knees) was further characterized on a self-reported severity scale of 1 (never) to 5 (very strongly) for each of the following symptoms: stinging pain, electric-like pain, burning pain, numbness, pain induced by mild stimulation (e.g. clothing touching the skin or cold wind), hypoesthesia or hyperesthesia in the painful area, and swelling or skin color change (red or purple) in the painful area (33). Only patients who reported a pain severity scale score of 2 (slightly) to 5 (very strongly) for the presence of bilateral foot pain (options 2-5 in Q5_1) were required to complete the remaining portion of the study.

Tree analyses were conducted to further clarify and categorize the experiences of patients with symptoms; these used survey questions that were asked independently, without consideration of the order of the questions. The first tree analysis considered patients who consulted a doctor and did not understand the causes of their pain. The second analysis considered patients who did not consult a doctor and did not understand the causes of their pain. The analyses then examined whether or not these subgroups of patients reported problems in daily life. 


\section{Data collection and management}

Data were collected between July 16 and 22, 2019, and the collection process is shown in a flow diagram (Supplementary material 2). This study was conducted with a onetime, approximately 10-minute-long anonymous (per the regulation of Rakuten Insight, Inc.) web questionnaire consisting of selected or text-filled items. The URL to the questionnaire was provided to each patient via email [the original Japanese questionnaire was based on the neuropathic pain screening questionnaire for Japanese patients with neuropathic pain published by the Japanese Society of Pain Clinicians (33) and is available as Supplementary material 1 (English version)]. Patients were to enter response data according to the explanatory text of the questionnaire, and the entered data were recorded and collected electronically. The responses were compiled and stored in a database. After it was confirmed by INTAGE Healthcare (IHC) (Tokyo, Japan) that the goal number of responses had been reached, the sponsor's (Daiichi Sankyo, Tokyo, Japan) approval was obtained to conclude data collection. IHC then compiled the questionnaire data, performed data clean-up, and reviewed the data entries before the final confirmation and database lock were performed by the data manager and statistical analysis manager. Correction of data was prohibited after this time.

For the primary endpoint, the number and percentage of patients with bilateral foot symptoms (yes or no) were tabulated for each of the following items: consultation with a doctor, degree of understanding of the disease, degree of effect on life, and degree of awareness of treatment. For the secondary endpoint, the number and percentage of patients who answered yes or no was determined for the following items: consultation with a doctor, understanding the cause of the disease, type of trouble the disease is causing in their daily life, and awareness of treatment for patients with bilateral foot symptoms.

\section{Statistical analyses}

The planned number of patients for this study was 5,500. Assuming that $20 \%$ of patients had symptoms in both feet, the target enrolment was based on an estimated 1,068 patients required to achieve the maximum width of the $95 \%$ confidence interval (CI) of each survey item within $\pm 3 \%$. Patients who met all inclusion criteria and none of the exclusion criteria were included in the analysis set. Categorical variables were summarized by the number and percentage of patients. As this is not a verification study but a survey to investigate the current status of suspected DPNP patients, no tests for statistical significance were performed. All statistical analyses were performed using the ASSUM software program for Windows, ver. 5.8 (Japan Information Processing Service, Tokyo, Japan).

\section{Results}

\section{Patients}

Of the 10,008 patients with diabetes mellitus who accessed the questionnaire, $8,930(89.2 \%)$ agreed to participate in this study. Patient and disease characteristics are reported in Table 1 . The majority of patients were male $(88.4 \%)$, between 50 and 69 years of age $(66.8 \%)$, with type 2 diabetes $(92.5 \%)$, and were never or ex-smokers $(72.8 \%)$. Overall, $22.3 \%$ of patients were diagnosed with diabetes in the last 5 years, while $27.2 \%$ were diagnosed over 15 years ago; the most recent $\mathrm{HbA} 1 \mathrm{c}$ values for $54.3 \%$ of patients were less than $7.0 \%$. The majority of patients had been treated in an internal medicine department $(57.5 \%)$ and in a clinic $(71.5 \%)$.

\section{Bilateral foot symptoms}

Among the 7,754 (86.8\%) patients meeting the inclusion criteria, 1,768 (22.8\%) had bilateral foot pain symptoms (below the knee), with the most common being intense numbness $[13.0 \%(1,008 / 7,754)]$ and stinging pain $[9.0 \%(700 /$ 7,754)] (Table 2). Among patients who reported having bilateral foot pain symptoms, for each pain symptom category, the most frequent severity of pain symptom reported was "slightly" versus "moderately", "strongly", and "very strongly". The majority of patients had symptoms that persisted for at least one year.

\section{Healthcare consultation}

Overall, 55.3\% (977/1,768) of patients with bilateral foot symptoms consulted a doctor regarding their symptoms; of those who did not, $89.4 \%$ (707/791) felt that they should not bother their doctors, as their symptoms were not severe enough to warrant a consultation (Table 3).

\section{Understanding of symptoms}

Overall, $59.9 \%(1,059 / 1,768)$ of patients with bilateral foot symptoms reported understanding the causes of their symptoms. Of these respondents, 58.8\% (623/1,059) and $31.4 \%(333 / 1,059)$ reported that the symptoms were attributed to neurologic deficits in diabetes and orthopedic disease, respectively (Table 3).

\section{Reported problems in daily life}

Approximately one-quarter of patients with bilateral foot symptoms reported that their symptoms affected their daily life $[25.9 \%(458 / 1,768)]$, with the most common effects being an inability to walk for long periods [58.3\% (267/458)] and feeling anxious [58.1\% (266/458)] (Table 3).

\section{Understanding of treatment}

Only $18.2 \%(322 / 1,768)$ of patients with bilateral foot symptoms recognized that treatments were available to manage their symptoms; of those respondents who knew that 
Table 1. Patient and Disease Characteristics.

\begin{tabular}{|c|c|}
\hline Characteristic & Patients $(\mathrm{n}=7,754)$ \\
\hline \multicolumn{2}{|l|}{ Sex } \\
\hline Male & $6,852(88.4)$ \\
\hline Female & $902(11.6)$ \\
\hline \multicolumn{2}{|l|}{ Age, years } \\
\hline 20 to 29 & $15(0.2)$ \\
\hline 30 to 39 & $160(2.1)$ \\
\hline 40 to 49 & $992(12.8)$ \\
\hline 50 to 59 & 2,449 (31.6) \\
\hline 60 to 69 & $2,734(35.3)$ \\
\hline 70 to 79 & $1,378(17.8)$ \\
\hline$\geq 80$ & $26(0.3)$ \\
\hline \multicolumn{2}{|l|}{ Area } \\
\hline Hokkaido & $395(5.1)$ \\
\hline Tohoku & $488(6.3)$ \\
\hline Kanto & 2,835 (36.6) \\
\hline Chubu & $1,271(16.4)$ \\
\hline Kinki & $1,589(20.5)$ \\
\hline Chugoku & $405(5.2)$ \\
\hline Shikoku & $181(2.3)$ \\
\hline Kyushu and Okinawa & $590(7.6)$ \\
\hline \multicolumn{2}{|l|}{ Type of diabetes } \\
\hline Type 1 & $359(4.6)$ \\
\hline Type 2 & $7,173(92.5)$ \\
\hline Unknown & $222(2.9)$ \\
\hline \multicolumn{2}{|l|}{ Years since diagnosis } \\
\hline$<5$ & $1,733(22.3)$ \\
\hline 5 to $<10$ & $2,191(28.3)$ \\
\hline 10 to $<15$ & $1,660(21.4)$ \\
\hline$\geq 15$ & $2,110(27.2)$ \\
\hline Unknown & $60(0.8)$ \\
\hline \multicolumn{2}{|l|}{ Recent HbA1c value } \\
\hline$<6.0 \%$ & $516(6.7)$ \\
\hline $6.0 \%$ to $<6.5 \%$ & $1,717(22.1)$ \\
\hline $6.5 \%$ to $<7.0 \%$ & $1,981(25.5)$ \\
\hline $7.0 \%$ to $<7.5 \%$ & $1,802(23.2)$ \\
\hline $7.5 \%$ to $<10.0 \%$ & $1,328(17.1)$ \\
\hline$\geq 10.0 \%$ & $109(1.4)$ \\
\hline Unknown & $301(3.9)$ \\
\hline \multicolumn{2}{|l|}{ Frequency of alcohol consumption } \\
\hline Do not drink & $2,721(35.1)$ \\
\hline Drink occasionally & $2,888(37.2)$ \\
\hline Drink every day & $2,145(27.7)$ \\
\hline \multicolumn{2}{|l|}{ Smoking status } \\
\hline Never & $3,746(48.3)$ \\
\hline Former smoker & $1,900(24.5)$ \\
\hline Current smoker & $2,108(27.2)$ \\
\hline \multicolumn{2}{|l|}{ Outpatient status } \\
\hline Visited hospital & 7,731 (99.7) \\
\hline On a home-visit basis & $23(0.3)$ \\
\hline Be hospitalized & $5(0.1)$ \\
\hline \multicolumn{2}{|l|}{ Clinical department } \\
\hline Diabetes & $2,920(37.8)$ \\
\hline Internal medicine & $4,446(57.5)$ \\
\hline Other & $365(4.7)$ \\
\hline \multicolumn{2}{|l|}{ Medical institution } \\
\hline Clinic & $5,524(71.5)$ \\
\hline University hospital & $427(5.5)$ \\
\hline Hospital other than university hospital & $1,752(22.7)$ \\
\hline Home-visit nursing station & $0(0.0)$ \\
\hline Healthcare facility for the elderly & $0(0.0)$ \\
\hline Other & $28(0.4)$ \\
\hline
\end{tabular}

Data are shown as $\mathrm{n}(\%)$.

HbAlc: hemoglobin Alc there were treatments available, oral medications [64.6\% (208/322)] were the most commonly recognized (Table 3).

\section{The tree analysis}

For the patients with symptoms who consulted a doctor regarding their foot symptoms, $11.8 \%(208 / 1,768)$ did not understand the cause of their foot symptoms, and $4.0 \%$ (70/ 1,768) reported having problems in their daily life (Figure a). For patients with foot symptoms who did not consult a doctor about their symptoms, 28.3\% (501/1,768) reported not understanding the cause of their pain, and 2.6\% (46/ 1,768) reported having problems in their daily life (Figure b).

\section{Discussion}

The significance of this observational study is that it provides a contemporary analysis of the current status of suspected DPNP in Japan using responses obtained from patients with diabetes in real-world clinical practice. Overall, $22.8 \%$ of respondents who met the study inclusion criteria reported having some kind of bilateral foot pain, suggesting that a potential diagnosis of DPNP should always be kept in mind in diabetes practice. Despite changes in available treatments, such as $\alpha_{2} \delta$ ligands and SNRIs $(13,16-18)$, since a large-scale Japanese survey was conducted between 2006 and $2007(14,27)$, the percentage of patients with pain symptoms did not notably differ between the two studies. This may indicate that the experience of patients with diabetes has not improved in the past decade, although how the extent of pain experienced was changed by the available treatment was unclear.

Our survey found that $54.3 \%$ of respondents' most recent HbA1c values were less than $7.0 \%$, which was similar to the finding from the previous study (45.3\%) (27). In the 2016/ 2017 guidelines for diabetes treatment in Japan, the management target value for HbA1c was set at less than $7.0 \%$ for the prevention of diabetes complications (16). Therefore, because at least half of respondents in our study had reached this HbA1c management target, a high level of diabetes control can be inferred.

Among the patients who reported having some kind of bilateral foot pain, most had slight pain. Although this study did not analyze the consultation status with a doctor according to the intensity of pain, it is speculated that the consultation status may differ depending on the intensity of pain. This is supported by our finding that nearly half (44.7\%) of respondents who answered that they had pain did not consult a doctor, with $89.4 \%$ of respondents indicating that this was because they did not feel that they had symptoms of sufficient severity to request a consultation. However, the consultation rate in this study was higher than that reported in a previous Japanese survey from 2012, in which 56\% of respondents indicated that they did not consult a doctor for their symptoms (14), suggestive of a slowly growing patient awareness of this condition and the possibility of obtaining 
Table 2. Patients Reporting Bilateral Foot (Below the Knees) Pain Symptoms and Persistence of Symptoms.

\begin{tabular}{|c|c|c|c|c|c|c|}
\hline \multirow[b]{3}{*}{ Pain symptoms } & \multirow[b]{3}{*}{ Overall } & \multicolumn{5}{|c|}{ Patients $(n=7,754)$} \\
\hline & & \multicolumn{5}{|c|}{ By severity } \\
\hline & & Never & Slightly & Moderately & Strongly & Very strongly \\
\hline Any pain symptoms & $1,768(22.8)$ & $5,986(77.2)$ & - & - & - & - \\
\hline Stinging pain & $700(9.0)$ & $7,054(91.0)$ & $556(7.2)$ & $97(1.3)$ & $25(0.3)$ & $22(0.3)$ \\
\hline Electric pain & $688(8.9)$ & $7,066(91.1)$ & $523(6.7)$ & $111(1.4)$ & $31(0.4)$ & $23(0.3)$ \\
\hline Burning pain & $339(4.4)$ & $7,415(95.6)$ & $237(3.1)$ & $63(0.8)$ & $23(0.3)$ & $16(0.2)$ \\
\hline Numbness & $1,008(13.0)$ & $6,746(87.0)$ & $687(8.9)$ & $197(2.5)$ & $80(1.0)$ & $44(0.6)$ \\
\hline $\begin{array}{l}\text { Pain induced by mild stimulation such as } \\
\text { clothing touching the skin or cold wind }\end{array}$ & $189(2.4)$ & $7,565(97.6)$ & $130(1.7)$ & $35(0.5)$ & $13(0.2)$ & $11(0.1)$ \\
\hline Hypoesthesia or hyperesthesia in the painful area & $671(8.7)$ & $7,083(91.3)$ & $457(5.9)$ & $137(1.8)$ & $44(0.6)$ & $33(0.4)$ \\
\hline $\begin{array}{l}\text { Swelling or skin color change (red or purple) in } \\
\text { the painful area }\end{array}$ & $543(7.0)$ & $7,211(93.0)$ & $365(4.7)$ & $115(1.5)$ & $35(0.5)$ & $28(0.4)$ \\
\hline \multicolumn{7}{|l|}{ Persistence of symptoms $(n=1,768)$} \\
\hline$<6$ months & \multicolumn{6}{|c|}{$245(13.9)$} \\
\hline 6 to $<12$ months & \multicolumn{6}{|c|}{$211(11.9)$} \\
\hline$\geq 12$ months & \multicolumn{6}{|c|}{$1,036(58.6)$} \\
\hline Unknown & \multicolumn{6}{|c|}{$276(15.6)$} \\
\hline
\end{tabular}

Data are shown as $\mathrm{n}(\%)$.

treatment.

It was found that $40.1 \%$ of respondents who indicated that they had some pain did not understand the cause of their pain. Compared with a previous study (74.0\%) (34), fewer respondents reported not understanding the cause of their pain symptoms in this study. In addition, greater numbers of patients reported consulting a doctor for their symptoms. These findings suggest that patient and doctor awareness can be improved. Furthermore, evidence suggests that improved patient awareness of the risk of neuropathy before its onset can substantially improve the motivation to start and adhere to anti-diabetic therapy $(28,29)$.

Overall, $25.9 \%$ of respondents said that they had some pain symptoms and had symptoms that caused problems in their daily lives, suggesting that there is a notable percentage of patients with diabetes mellitus who have disabling symptoms associated with DPNP. The number of patients reporting problems in their daily lives who did not consult a doctor was 83 (Supplementary material 3), corresponding to $18.1 \%$ of all respondents who answered that they had some pain symptoms and had symptoms causing problems in their daily lives. These findings support the importance of a diagnosis in such patients so that they can receive timely and appropriate treatment.

The findings from the tree analysis allow us to make further inferences from the patient responses and confirm some of the key unmet needs for patients that remain to be addressed to improve their experiences and outcomes. For patients with symptoms who consulted a doctor regarding their foot symptoms, $11.8 \%$ did not understand the cause of their foot symptoms, and $4.0 \%$ reported having problems in their daily life. In addition, for symptomatic patients who did not consult a doctor about their symptoms, $28.3 \%$ did not understand the cause of their pain, and $2.6 \%$ reported having problems in their daily life. These findings also indicate the importance of improving patient understanding of their pain symptoms and of accurately diagnosing DPNP. Furthermore, a similar percentage of patients who consulted a doctor reported problems in their daily life irrespective of their understanding of the causes of their pain, suggesting that understanding their condition does not affect associated problems with their daily life.

Although there is no international consensus concerning the diagnosis of DPN, the 2016 JDS guidelines $(13,16)$ recommend the diagnostic standard or the simplified diagnostic standard from the Toronto Diabetic Neuropathy Expert Group (35). In addition to the confirmation of subjective symptoms, simple neurological examinations are specified, and a heart rate variability test is considered useful as an autonomic nervous function test. However, because these tests require time and proficiency to perform, it may be difficult to diagnose DPN in many patients with diabetes, particularly in outpatient settings. Thus, the use of a questionnaire to determine the presence of suspected DPNP through the presence of subjective symptoms, as was used in our study, is expected to support a clinical diagnosis.

A strength of this study was the large sample size. In addition, although this survey investigated the prevalence and type of pain in patients with diabetes, it did not evaluate pain scores using a particular scale; thus, the research conditions were similar to prior Japanese studies, allowing us to more easily make comparisons and identify changes since the publication of previous data.

Several limitations associated with the present study warrant mention. First, compared with clinical trials, crosssectional studies such as ours carry limitations inherent to the study design, including a risk of bias. Second, most of the patients included in this study were men and under 80 
Table 3. Survey Results.

\begin{tabular}{|c|c|}
\hline Outcome & Patients \\
\hline \multicolumn{2}{|l|}{ Healthcare consultation } \\
\hline Have you consulted a doctor about your foot symptoms? & $\mathrm{n}=1,768$ \\
\hline Yes & $977(55.3)$ \\
\hline No & $791(44.7)$ \\
\hline $\begin{array}{l}\text { Please select the most appropriate reason for why you have not consulted } \\
\text { a doctor for your foot symptoms }\end{array}$ & $\mathrm{n}=791$ \\
\hline Not troubled enough to consult a doctor & $707(89.4)$ \\
\hline The doctor looked busy & $19(2.4)$ \\
\hline Other & $65(8.2)$ \\
\hline \multicolumn{2}{|l|}{ Understanding of symptoms } \\
\hline Do you understand the cause of your foot symptoms? & $\mathrm{n}=1,768$ \\
\hline Yes & $1,059(59.9)$ \\
\hline No & $709(40.1)$ \\
\hline What do you understand to be the cause of your foot symptoms? & $\mathrm{n}=1,059$ \\
\hline Because of diabetic neuropathy & $623(58.8)$ \\
\hline Because of orthopedic disease & $333(31.4)$ \\
\hline Other & $103(9.7)$ \\
\hline \multicolumn{2}{|l|}{ Problems in daily life } \\
\hline Do your foot symptoms affect your daily life? & $\mathrm{n}=1,768$ \\
\hline Yes & $458(25.9)$ \\
\hline No & $1,310(74.1)$ \\
\hline $\begin{array}{l}\text { What problems in your daily life do you experience because of your foot } \\
\text { symptoms? }\end{array}$ & $\mathrm{n}=458$ \\
\hline Cannot walk for long periods & $267(58.3)$ \\
\hline Feeling anxious & $266(58.1)$ \\
\hline Everyday life is restricted & $164(35.8)$ \\
\hline Sleep is disturbed & 137 (29.9) \\
\hline Other & $22(4.8)$ \\
\hline \multicolumn{2}{|l|}{ Understanding of treatment } \\
\hline Do you know that there are treatments to improve your foot symptoms? & $\mathrm{n}=1,768$ \\
\hline Yes & $322(18.2)$ \\
\hline No & $1,446(81.8)$ \\
\hline $\begin{array}{l}\text { Which of the following do you understand to be treatments to improve } \\
\text { your foot symptoms? }\end{array}$ & $\mathrm{n}=322$ \\
\hline Oral medicine & $208(64.6)$ \\
\hline Compresses and patch medicines & $40(12.4)$ \\
\hline Acupuncture and moxibustion massage & $22(6.8)$ \\
\hline Injections & $17(5.3)$ \\
\hline Other & $35(10.9)$ \\
\hline
\end{tabular}

Data are shown as $\mathrm{n}(\%)$.

years old. This bias in terms of sex and age was due to bias in the Rakuten panel used in this study. While the reason for the sex-based bias in the Rakuten panel is unknown, the selection bias in terms of age may have been related to the internet usage rate. According to data released by the Japanese Ministry of Internal Affairs and Communications, the internet usage rate for people $\geq 80$ years old in Japan is low, at about $20 \%$ (36), which may explain the low proportion of elderly patients in the present study. Third, we used a webbased survey, which may also have inherent limitations in terms of objectivity. The accuracy of the results compared with actual clinical practice might be limited, and there is the possibility of selection bias, as a web-based survey is more likely to be completed by patients who have familiar- ity with online applications (younger versus older patients). Thus, this posed a disadvantage to the already low proportion of older patients registered in the Rakuten panel. Fourth, patients who self-reported diabetes were asked to complete the neuropathic pain questionnaire on their own, which means that the findings are from the patient's own subjective responses without a confirmation of a diagnosis by a doctor; therefore, this study may include patients who do not have DPNP according to the current diagnostic criteria. Fifth, in this study, approximately $30 \%$ of respondents indicated that their pain was caused by an orthopedic disease. The reason for each response was also not explored in detail, so this underlying information remains unknown. However, older patients ( $>50$ years old) may suffer from 
a

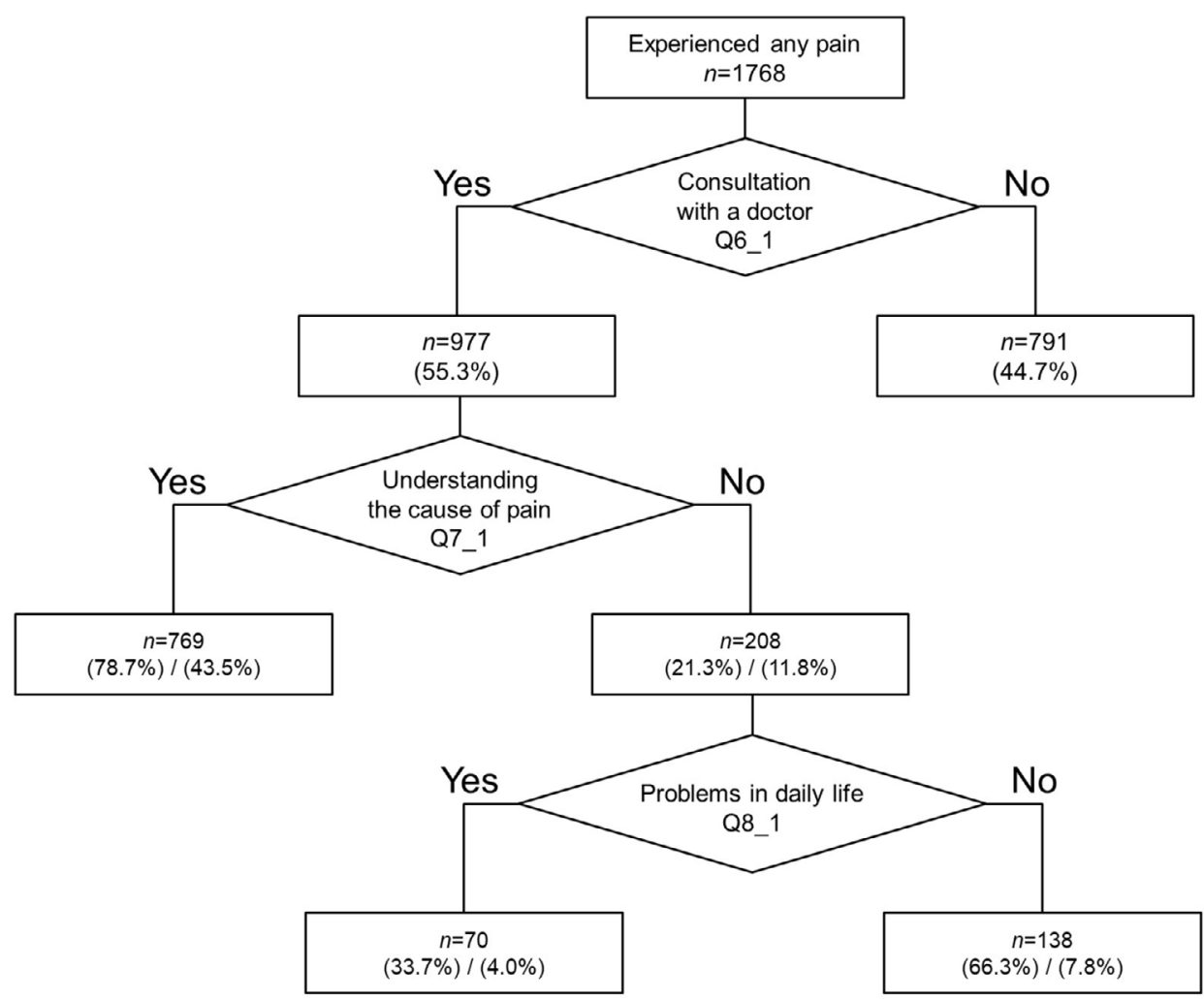

b
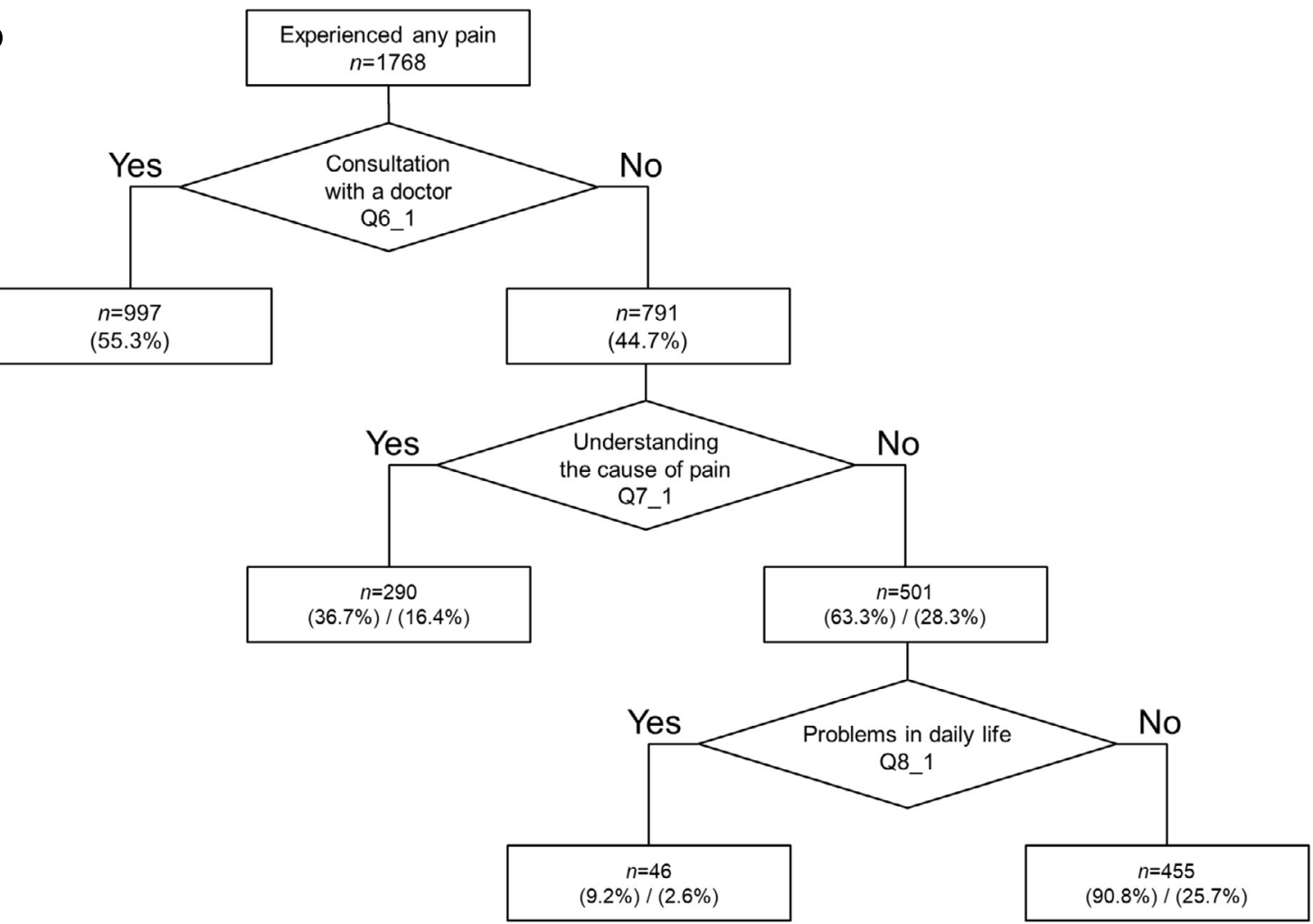

Figure. The tree analyses a) of patients who experienced any pain and consulted a doctor (Q6_1) but did not understand the cause of pain (Q7_1) and had problems in their daily life (Q8_1) and b) of patients who experienced any pain but had not consulted a doctor (Q6_1) nor understood the cause of their pain (Q7_1) and had problems in their daily life (Q8_1). Percentages are shown as (\% of the patients in this hierarchy $) /(\%$ of patients with any pain, $n=1,768)$. 
foot pain symptoms due to underlying orthopedic disease, and it is important to evaluate such patients carefully in order to administer appropriate treatment. Sixth, we did not analyze the results of each questionnaire by pain intensity and type. Seventh, we did not investigate any correlation between the severity of pain and consultation with a doctor, nor whether or not the study population was receiving treatment for painful symptoms, and if they were, whether or not such treatment had an effect. We also did not evaluate whether or not patients who did not report symptoms were already receiving treatment with SNRIs or $\alpha_{2} \delta$ ligands. The lack of information on current treatment for pain symptoms may have interfered with the self-reporting of pain. Eighth, we did not evaluate whether or not patients who had been diagnosed with DPN had an understanding of the causes of their symptoms. Finally, while the questionnaires used in the present study were based on Japanese guidelines, these questionnaires are not considered validated instruments for diagnoses.

\section{Conclusion}

In conclusion, our study indicated that $22.8 \%$ of patients with diabetes have symptoms of bilateral foot pain and that this percentage has not changed appreciably in the past decade, despite good glycemic control and the introduction of new therapies. In addition, approximately one-quarter of patients indicated that their symptoms affected their daily life. DPNP is probably underdiagnosed as some patients do not receive a medical consultation despite having problems in their daily lives caused by their symptoms, and some patients do not understand the cause of their symptoms. It is important for doctors to actively question their patients with diabetes in order to identify those with DPNP that may adversely affect their QOL.

All procedures were in accordance with the ethical standards of the responsible committee on human experimentation (institutional and national) and/or with the 1964 Declaration of Helsinki and later versions. This study was also conducted in accordance with the Japanese ethical guidelines for medical and health research involving human subjects (37), the Act on the Protection of Personal Information, and the revised Personal Information Protection Act. Ethics review board approval by the Clinical Research Promotion Network Japan (approval number: not specified) was obtained on May 23, 2019, before conducting the study.

Informed consent was obtained from all patients who participated in this study.

Author's disclosure of potential Conflicts of Interest (COI). Hideyuki Sasaki: Honoraria, Daiichi Sankyo. Hiroshi Takatsuna: Employment, Daiichi Sankyo. Teruyoshi Inoue: Employment, Daiichi Sankyo. Daiju Matsui: Employment, Daiichi Sankyo. Hiroshi Sakoda: Employment, Daiichi Sankyo. Mizuka Yokoyama: Employment, Daiichi Sankyo. Kazuhito Shiosakai: Employment,
Daiichi Sankyo. Haruhiko Seki: Employment, INTAGE Healthcare. Yoshiyuki Uetake: Employment, INTAGE Healthcare. Kaoru Okuizumi: Employment, Daiichi Sankyo.

\section{Financial Support}

This study and medical writing were funded by Daiichi Sankyo Co., Ltd., Tokyo, Japan.

\section{Acknowledgement}

The authors would like to thank Tricia Newell, $\mathrm{PhD}$, for providing medical writing assistance.

\section{References}

1. Vinik AI, Nevoret ML, Casellini C, Parson H. Diabetic neuropathy. Endocrinol Metab Clin North Am 42: 747-787, 2013.

2. Pop-Busui R, Boulton AJ, Feldman EL, et al. Diabetic neuropathy: a position statement by the American Diabetes Association. Diabetes Care 40: 136-154, 2017.

3. Gregg EW, Gu Q, Williams D, et al. Prevalence of lower extremity diseases associated with normal glucose levels, impaired fasting glucose, and diabetes among U.S. adults aged 40 or older. Diabetes Res Clin Pract 77: 485-488, 2007.

4. Alleman CJ, Westerhout KY, Hensen M, et al. Humanistic and economic burden of painful diabetic peripheral neuropathy in Europe: a review of the literature. Diabetes Res Clin Pract 109: 215-225, 2015.

5. Satoh J, Baba M, Yagihashi S, et al. Frequency of diabetic polyneuropathy (DPN) and clinical significance of achilles tendon reflex in diagnosis of DPN -Survey of 15,000 patients in Tohoku, Japan. Journal of the Japan Diabetes Society 50: 799-806, 2007 (in Japanese, Abstract in English).

6. Goto Y. Research about diabetic neuropathy. The Journal of Japan Physicians Association 17: 125-138, 2002 (in Japanese, Abstract in English).

7. Yokoyama H, Tsuji T, Hayashi S, Kabata D, Shintani A. Factors associated with diabetic polyneuropathy-related sensory symptoms and signs in patients with polyneuropathy: a cross-sectional Japanese study (JDDM 52) using a non-linear model. J Diabetes Investig 11: 450-457, 2019.

8. Gylfadottir SS, Weeracharoenkul D, Andersen ST, Niruthisard S, Suwanwalaikorn S, Jensen TS. Painful and non-painful diabetic polyneuropathy: clinical characteristics and diagnostic issues. J Diabetes Investig 10: 1148-1157, 2019.

9. Gore M, Brandenburg NA, Dukes E, Hoffman DL, Tai KS, Stacey B. Pain severity in diabetic peripheral neuropathy is associated with patient functioning, symptom levels of anxiety and depression, and sleep. J Pain Symptom Manage 30: 374-385, 2005.

10. Tesfaye S, Vileikyte L, Rayman G, et al. Painful diabetic peripheral neuropathy: consensus recommendations on diagnosis, assessment and management. Diabetes Metab Res Rev 27: 629-638, 2011.

11. Girach A, Julian TH, Varrassi G, Paladini A, Vadalouka A, Zis P. Quality of life in painful peripheral neuropathies: a systematic review. Pain Res Manag 2019: 2091960, 2019.

12. Herman WH, Kennedy L. Underdiagnosis of peripheral neuropathy in type 2 diabetes. Diabetes Care 28: 1480-1481, 2005.

13. Japan Diabetes Society. Diabetes Care Guidelines 2016 [Internet]. [cited 2020 Jan 21]. Available from: https://minds.jcqhc.or.jp/n/me d/4/med0004/G0000893/0001

14. Japanese Medical Association. Japan Promotion Council for Diabetes Prevention and Countermeasures. Report on Abnormalities in Foot Appearance and Diabetic Neuropathy in Diabetes 2008 [Internet]. [cited 2020 Jan 21]. Available from: http://dl.med.or.jp/dlmed/tounyoubyou/diabetes080312.pdf (in Japanese). 
15. Tsuji M, Yasuda T, Kaneto H, et al. Painful diabetic neuropathy in Japanese diabetic patients is common but underrecognized. Pain Res Treat 2013: 318352, 2013.

16. Japan Diabetes Society. Treatment Guide for Diabetes 2016-2017 [Internet]. [cited 2020 Jan 21]. Available from: http://www.fa.kyori n.co.jp/jds/uploads/Treatment_Guide_for_Diabetes_2016-2017.pdf

17. Baba M, Matsui N, Kuroha M, Wasaki Y, Ohwada S. Mirogabalin for the treatment of diabetic peripheral neuropathic pain: a randomized, double-blind, placebo-controlled phase III study in Asian patients. J Diabetes Investig 10: 1299-1306, 2019.

18. Colloca L, Ludman T, Bouhassira D, et al. Neuropathic pain. Nat Rev Dis Primers 3: 17002, 2017.

19. Max MB, Culnane M, Schafer SC, et al. Amitriptyline relieves diabetic neuropathy pain in patients with normal or depressed mood. Neurology 37: 589-596, 1987.

20. Freeman R, Durso-Decruz E, Emir B. Efficacy, safety, and tolerability of pregabalin treatment for painful diabetic peripheral neuropathy: findings from seven randomized, controlled trials across a range of doses. Diabetes Care 31: 1448-1454, 2008.

21. Satoh J, Yagihashi S, Baba M, et al. Efficacy and safety of pregabalin for treating neuropathic pain associated with diabetic peripheral neuropathy: a 14 week, randomized, double-blind, placebo-controlled trial. Diabet Med 28: 109-116, 2011.

22. Pritchett YL, McCarberg BH, Watkin JG, Robinson MJ. Duloxetine for the management of diabetic peripheral neuropathic pain: response profile. Pain Med 8: 397-409, 2007.

23. Yasuda H, Hotta N, Nakao K, Kasuga M, Kashiwagi A, Kawamori R. Superiority of duloxetine to placebo in improving diabetic neuropathic pain: results of a randomized controlled trial in Japan. J Diabetes Investig 2: 132-139, 2011.

24. Griebeler ML, Morey-Vargas OL, Brito JP, et al. Pharmacologic interventions for painful diabetic neuropathy: an umbrella systematic review and comparative effectiveness network meta-analysis. Ann Intern Med 161: 639-649, 2014.

25. Snedecor SJ, Sudharshan L, Cappelleri JC, Sadosky A, Mehta S, Botteman M. Systematic review and meta-analysis of pharmacological therapies for painful diabetic peripheral neuropathy. Pain Pract 14: 167-184, 2014.

26. Vilar S, Castillo JM, Munuera Martinez PV, Reina M, Pabón M. Therapeutic alternatives in painful diabetic neuropathy: a metaanalysis of randomized controlled trials. Korean J Pain 31: 253260, 2018.

27. Ono $\mathrm{H}$, Inoue $\mathrm{T}$, Hatakeyama $\mathrm{N}$, et al. Patient questionnaire survey on diabetic neuropathic pain. Progress in Medicine 28: 1199-1206,
2008 (in Japanese, Abstract in English).

28. Kubo T, Okuyama K, Zhao X, Singh S, Tokita S. Factors associated with reluctance to initiate or continue oral antihyperglycemic agent (OAHA) treatments in type 2 diabetes mellitus patients in Japan: an observational patient-reported study. Diabetes Metab Syndr 13: 1201-1207, 2019.

29. Reach G, Le Pautremat V, Gupta S. Determinants and consequences of insulin initiation for type 2 diabetes in France: analysis of the National Health and Wellness Survey. Patient Prefer Adherence 7: 1007-1023, 2013.

30. Cepeda MS, Wilcox M, Levitan B. Pain qualities and satisfaction with therapy: a survey of subjects with neuropathic pain. Pain Med 14: 1745-1756, 2013.

31. Lopez JMS, Bailey RA, Rupnow MFT, Annunziata K. Characterization of type 2 diabetes mellitus burden by age and ethnic groups based on a nationwide survey. Clin Ther 36: 494-506, 2014.

32. Rakuten Insight, Inc. Rakuten Insight [Internet]. [cited 2020 Jan 21]. Available from: https://insight.rakuten.co.jp/en/

33. Japan Society of Pain Clinicians. Guidelines for the Pharmacologic Management of Neuropathic Pain (Second Edition) 2016 [Internet]. [cited 2020 Jan 21]. Available from: http://minds4.jcqhc. or.jp/minds/Pharmacologic-management-of-neuropathic-pain/Pharm acologic-Management-of-Neuropathic-pain-ENGver.pdf

34. Shionogi \& Co., Ltd., \& Eli Lilly Japan K.K. Press release: Disease awareness campaign for diabetic neuropathy 2013 [Internet]. [cited 2020 Jan 21]. Available from: https://www.shionogi.co.jp/co mpany/news/2013/qdv9fu000000804o-att/130603-3.pdf

35. Tesfaye S, Boulton AJM, Dyck PJ, et al. Diabetic neuropathies: update on definitions, diagnostic criteria, estimation of severity, and treatments. Diabetes Care 33: 2285-2293, 2010.

36. Japanese Ministry of Internal Affairs and Communications. Data from the 2018 Survey of Trends in Digital Communications Usage [Internet]. [cited $2020 \mathrm{Jul}$ 1]. Available from: https://www.soumu.g o.jp/johotsusintokei/statistics/data/190531_1.pdf (in Japanese).

37. Japan Ministry of Heath Labour and Welfare. Ethical guidelines for medical and health research involving human subjects 2015 [Internet]. [cited 2020 Jan 21]. Available from: https://www.mhlw. go.jp/file/06-Seisakujouhou-10600000-Daijinkanboukouseikagakuk a/0000080278.pdf

The Internal Medicine is an Open Access journal distributed under the Creative Commons Attribution-NonCommercial-NoDerivatives 4.0 International License. To view the details of this license, please visit (https://creativecommons.org/licenses/ by-nc-nd/4.0/).

(C) 2021 The Japanese Society of Internal Medicine Intern Med 60: 357-365, 2021 